Original Research Paper

\title{
Horizontal Cooperation Practices in Internet-based Higher Education, Computational Logistics and Telecommunications
}

\author{
${ }^{1}$ Jesica de Armas, ${ }^{2,4}$ Thanasis Daradoumis, ${ }^{3}$ Anastasios A. Economides and ${ }^{4}$ Angel A. Juan \\ ${ }^{1}$ Department of Economics and Business, University Pompeu Fabra, Barcelona, Spain \\ ${ }^{2}$ Cultural Technology and Communication Department, University of the Aegean, Mytilene, Greece \\ ${ }^{3}$ Information Systems Department, University of Macedonia, Hellas, Greece \\ ${ }^{4}$ IN3-Computer Science Department, Open University of Catalonia, Barcelona, Spain
}

Article history

Received: 29-10-2018

Revised: $31-10-2018$

Accepted: 30-01-2019

Corresponding author:

Angel A. Juan

IN3-Computer Science

Department, Open University

of Catalonia, Barcelona, Spain

Email: ajuanp@uoc.edu

\begin{abstract}
Globalization and advances in information and communication technologies have boosted the use of Horizontal Cooperation (HC) practices in many industry sectors. In the current international market, these 'alliances' become especially relevant for small and medium organizations, which are forced to compete with large-scale corporations. This paper analyzes benefits and challenges of $\mathrm{HC}$ practices in three service sectors that are critical for most developed and emerging countries: Internet-based higher education, computational logistics and transportation and telecommunication services. The paper discusses the role of $\mathrm{HC}$ to benefit from economies of scale and reduce costs, improve quality of service and become more environmentally friendly. Hence, by using $\mathrm{HC}$ firms not only increase their competitiveness and extend their markets but, in addition, they also promote social responsiveness actions.
\end{abstract}

Keywords: Horizontal Cooperation, Internet-based Higher Education, Computational Logistics and Transportation, Telecommunications

\section{Introduction}

In our global economy, Small and Medium Enterprises (SMEs) need to continuously innovate in services and strategies to be more competitive and meet their customers' expectations in terms of service level and quality. Information and communication technologies, such as the Internet and the use of cloud computing or web-based information systems, allow SMEs to stablish cooperation alliances that benefit from economies of scale, thus reducing their operating cost and becoming more efficient and competitive. Hence, SMEs can develop Horizontal Cooperation (HC) practices with other partners located at the same stage of the supply chain (Bahinipati et al., 2009). The cooperating partners sharing information, resources and/or facilities can be either competitors or companies offering different types of services in the same or different markets. The main purpose of $\mathrm{HC}$ is then to reduce their operating costs while improving the quality of service they offer. However, HC can also have positive effects (externalities) over the environmental impact of some industries. As pointed out by Özener and Ergun (2008), trust issues take an important role in HC. Typically, lack of trust in other partners is the main obstacle to overcome before implementing this praxis.
The computation complexity of quantifying the economic benefits derived from $\mathrm{HC}$ is an additional obstacle, as well as the difficulty in reaching an agreement on how to redistribute these benefits among the different partners. In practically any field, $\mathrm{HC}$ can lead to economic benefits due to sharing risk, making cost savings, increasing investments, pooling know-how, enhancing product quality and variety and launching innovation faster. In contrast, $\mathrm{HC}$ can lead to competition problems where it causes negative market effects with respect to prices, output, innovation or the variety and quality of products. In general, when applying $\mathrm{HC}$, the substantial clauses of the agreement between companies may include policies regarding pricing, production and distribution. The agreement may also include sharing of information regarding the products and the market. Sometimes, HC agreements can violate the antitrust laws because these agreements may include clauses that restrict competition. This can change market dynamics in ways that can lead to higher prices, fewer or lower quality goods or services, or even less innovation. However, the Federal Trade Commission (2010) has developed the "Horizontal Merger Guidelines" that set out the agencies' analytical framework and provides many specific examples of how HC principles should be applied. 
The contents of this paper are organized as follows: $\mathrm{HC}$ opportunities in the Internet-based higher education sector are analyzed first; then, reviews on HC actions in the logistics and transportation sector are described; next, a similar analysis is completed for $\mathrm{HC}$ options in the telecommunication sector; at this point, some common patterns in the three sectors are identified and discussed; finally, the main conclusions of this work are highlighted.

\section{HC in Internet-Based Higher Education}

Computers and the Internet are transforming the way higher education is delivered in most universities worldwide. These tools allow for new cooperation opportunities among different institutions and countries. $\mathrm{HC}$ in higher education follows a rather complex multilateral pattern that involves knowledge exchange. For this reason, it is important to explicitly establish who possesses what information, in what format, how to access it in a timely manner and how to share it effectively. HC can be nonhierarchical and may involve multiple stakeholders across multiple levels, seeking to create new partnerships and promote collaboration, including south-south exchanges (Engel et al., 2014). Moreover, it contributes to the development of new communities of practice and Internet-based networks, which allow educational stakeholders to engage, interact and exchange information in a cost-effective way. Finally, we distinguish different modalities of $\mathrm{HC}$ : online and blended/on-site cooperation, as well as cooperation that involves two parties (bidirectional) or multiple parties (multidirectional). HC in education aims at developing mechanisms that enhance communication, as well as collaboration, in common tasks and projects among partners that belong to developed and less developed countries. It consists in working on common problems to find globally accepted solutions, whereas each partner learns by sharing its experience to each other in a smoother and more efficient way during all the different development phases. HC practices related to Internet-based higher education have started to appear all over the world. Figure 1 illustrates an example of such an experience in which two universities from different regions offer a joint degree online to students all around the world.

In the American continent, there has been an initial effort in Brazil at the graduate education level. Thus, Morosini (2011) considered sources from several institutional reports to analyze studies about bilateral and multilateral agreements, foreigners with scholarship in the country and Brazilians with scholarship in other countries. The results showed the coexistence of two internationalization models: the predominance of the traditional international cooperation, based on competition and collocation in the globalized labor market and the tendency of the horizontal international model, based on the international awareness and the willingness to strengthen the endogenous scientific capacity of the weakest members. Daniel (2012) describes how Brazilian academy training achieved to fulfill its needs through the establishment of a state policy that let Brazilian students circulate all around the world.

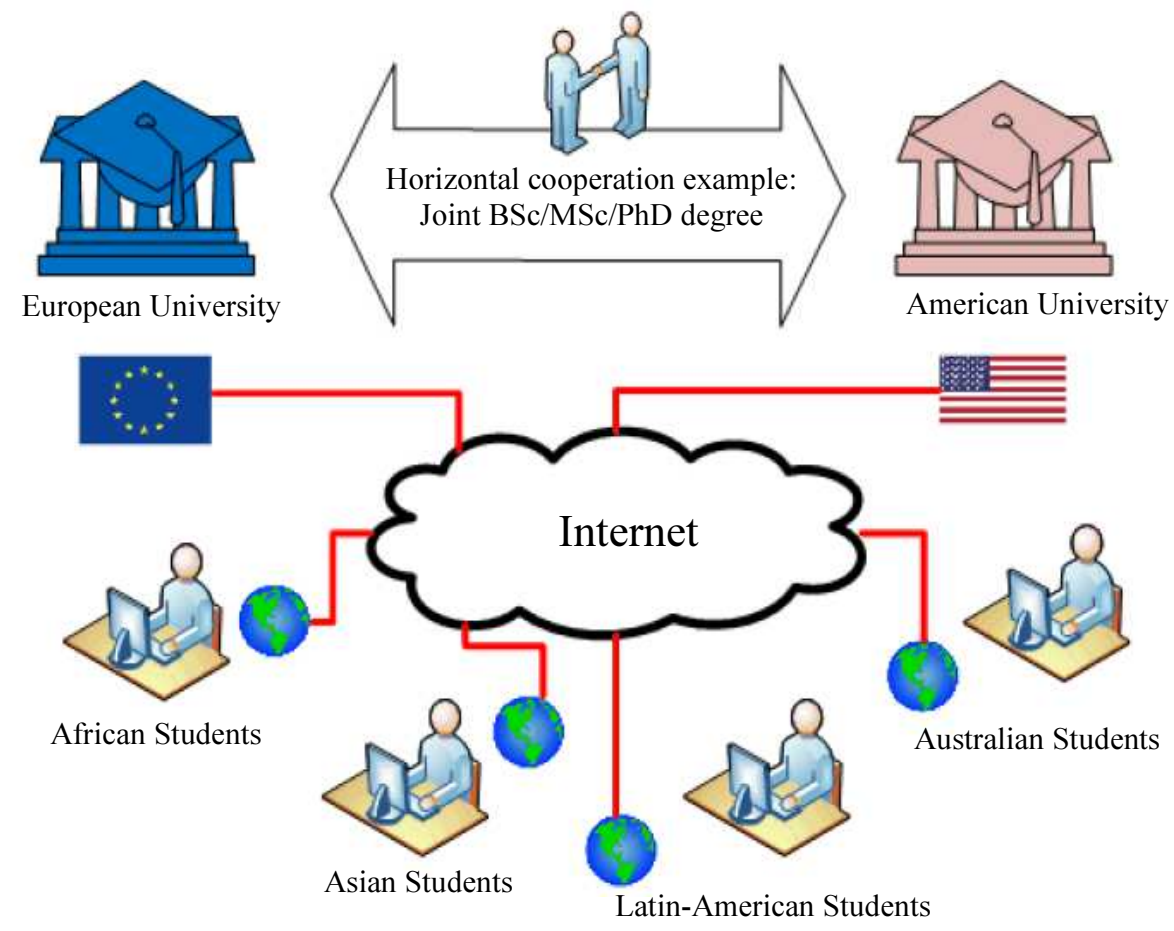

Fig. 1: An example of $\mathrm{HC}$ action in Internet-based higher education 
Moreover, Brazil gained several thousands of international students, especially from South America and sub-Saharan Africa, who wanted to carry out undergraduate and graduate training, by investing a great amount of resources. Therefore, this kind of cooperation not only achieved to strengthen ties with other developing countries in the south, but also established relationships which can be characterized more egalitarian than those between south and north countries. The analysis of this south to south migration showed that there may be complex and dynamic ways to control and influence international relations that lead to successful HC experiences. Rosen and Vilela (2011) define Horizontal Cooperation in Teacher Education (HCTE) as a theory of instructor professional development that applies HC systems to his/her professionalization field. They suggest that HCTE occurs when two or more educational stakeholder organizations, involved in the preparation of classroom teachers, form a cooperative association to share resources, increase teachers' preparation effectiveness and/or improve collective responsiveness to local or global educational challenges. Successful HC experiences are then supported by three systems: a shared leadership system, a knowledge exchange system and a capacity building system. These systems are designed to be used by leaders who are experts and are willing to offer their experience and knowledge to others. The whole system should be flexible and enable the exchange of roles of leadership and collaboration. Engel et al. (2014) analyzed how teachers can play an important role in enhancing quality education in the Caribbean and Latin America. They examined how new forms of multilateral education policy circulation and regional $\mathrm{HC}$ strategies have guided teacher education and professional development, leading to enhance both educational equity and quality.

Moving to the Asian continent, we can identify a few efforts related to $\mathrm{HC}$ experiences in higher education. These are based on education development projects, such as the south-south cooperation of the Korea International Cooperation Agency in Bangladesh, which aimed to build horizontal partnerships with shared ownership and mutual accountability and the Japan International Cooperation Agency. The later explored all education levels starting from primary education to university, including adult classes and contributed to improve education standards for both students and teachers throughout Africa.

Another example of HC system in higher education is presented from an Asian-African point of view. King (2014) examines the $20+20$ project, which linked twenty colleges or universities in China with an equivalent number in Africa. The study explored several programs that involved short- and long-term training of Africans in stand-alone projects and Confucius institutes in China, which shows that China really invested in human resource development in African higher education. It distinguishes the way China achieves to stay stable and on an apparently symmetrical status, when providing educational aid that contributes to common good and mutual benefit, though this financial participation is in fact unilateral. The success of China in this matter has been established by the fact that China was able to convince Kenya and other countries in Africa, that it was not going to take advantage of this situation. On the contrary, it aimed to function under a scheme of mutual respect, as a partner whose only goal was to contribute to others' development (Amutabi, 2013). As King (2014) state, the term 'mutual' predominates in both benefit and respect, as the result from the collaboration among administrators and academics in this partnership.

In Europe, $\mathrm{HC}$ in Internet-based higher education has been in an advantageous position due to an easier availability of financial and technological resources, research programs and a more privileged access to information networks. However, a challenge still remains at the level where $\mathrm{HC}$ should be structured on networks and community spaces that work in collaboration without losing their respective institutional identities. Most importantly, universities, either public or private, should emphasize public service. That is, university autonomy and cooperation should focus on the social endeavor of the university (Allen et al., 2012). The European Union established a horizontal policy, called Erasmus Mundus, with the aim to reinforce intercultural relations with third countries as well as to further improve the quality of knowledge-based economy of European countries. A study conducted by Guijarro et al. (2009) evaluated twelve Erasmus Mundus Master courses all round Europe and revealed an influencing impact on the quality of $\mathrm{HC}$ among higher education institutes. One of its main benefits has been to give a unique opportunity to many higher education departments to get to know the way students from thirdcountries work and thus be able to adapt their administrative policies and tasks in order to help these students in a more effective way. The Erasmus Mundus program has also been seen by Australian academy as an important means for achieving and consolidating academic excellence in higher education, as well as for promoting and enhancing collaboration with European institutions. Erasmus Mundus has also supported the ACCESS project (ACCESS, 2010), which involved horizontal cooperation between higher education institutions from South East Asia (SEA) and Europe. Its aim was to promote and build a common higher education area between SEA and EU to promote dialogue that could help European institutions to understand the way SEA higher education members perceive the European higher education system, thus promoting more effective collaborative structures among them.

Another dimension in international cooperation is provided by a study on internationalization in higher education in the Nordic countries (Maassen et al., 2005). This study includes 9 higher education institutions in 
Denmark, Sweden, Norway, Finland and Iceland. It analyzes how the growing "economization" and "marketization" of society has influenced both the internationalization strategies of higher education institutions and their academic goals. Furthermore, these authors presented several policy recommendations to support and increase the Nordic cooperation in higher education. A further example of $\mathrm{HC}$ system in higher education is provided by the Nordplus Higher Education Program (NORDPLUS, 2014), which concerns only the Nordic and Baltic countries and includes both bachelor and master levels. Under this HC program, higher education institutions can cooperate with other organizations building different types of activities, such as conferences, seminars, workshops, development of learning materials, course construction, exploitation and dissemination of educational experiences and learning outcomes. Finally, Guri-Rosenblit (2005) highlights how European universities may individually strive to achieve international recognition for high-quality studies, attract better students, provide mobilization facilities to their faculty members, etc. In contrast, they show an increasing willingness to collaborate both in research, through conducting collaborative research projects and preparing doctoral students and in teaching, through students' mobility, quality assurance mechanisms, more homogeneous and articulated degree systems, joint master degrees, etc.

\section{HC in Logistics and Transportation}

HC practices among transportation carriers allows reducing empty backhauls -i.e., return trips without cargo, which represent a noticeable amount of transportation activities in regions such as Europe and China. As highlighted by Bayliss et al. (2012), in some of these regions there are regulations that aim at promoting $\mathrm{HC}$ by allowing carriers to pick up cargo in foreign countries, thus avoiding empty backhauls during the returning trip home. Figure 2 illustrates an example of $\mathrm{HC}$ in which two warehouses (from different companies) share vehicles and optimize routing plans to avoid empty backhauls.

Peetijade and Bangviwat (2012) analyzed a case on $\mathrm{HC}$ in Thailand. Their work shows the existence of a large percentage of empty backhauls, which implies unnecessary emission of gasses and, of course, the existence of inefficiencies in the transportation system. As their study shows, traffic congestion and pollution would greatly benefit form horizontal cooperation practices. In countries such as the USA or Germany, HC is growing in popularity among transportation carriers, since it is seen as a way to offer better services to customers (Schmoltzi and Wallenburg, 2011).

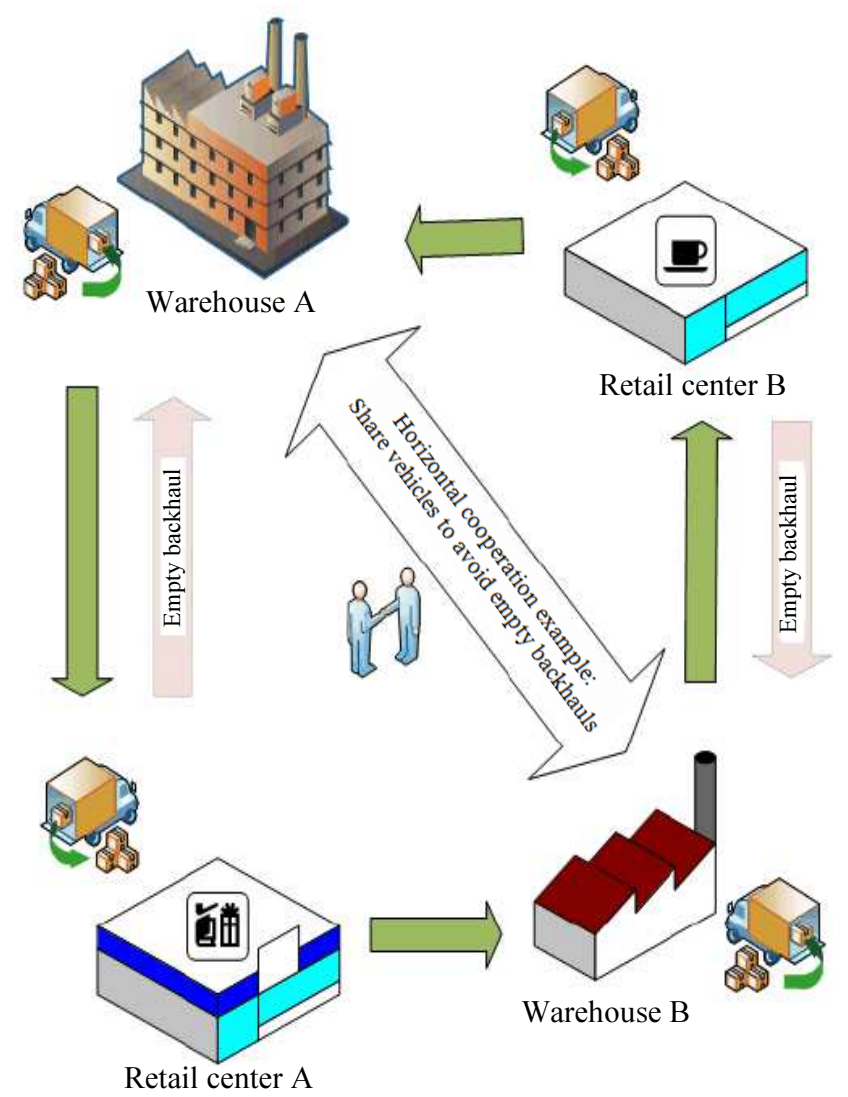

Fig. 2: An example of HC action in computational logistics to avoid empty backhauls by sharing routing plans 
Likewise, most governments in developed countries are promoting $\mathrm{HC}$ experiences as a way to improve not only competitiveness but also environmental sustainability among enterprises in the transportation and logistics sector. In effect, transportation activities account for a large percentage of greenhouse gas emissions in most developed regions. $\mathrm{HC}$ in the transportation and logistics industry not only can contribute to reduce operating costs -thus increasing competitiveness of partners-, but it can also be an effective measure to reduce the environmental impact of transportation activities. This goal is indirectly attained by making a more efficient use of the existing resources, e.g.: by eliminating unnecessary trips throughout backhauling strategies and by optimizing routing plans. Hence, some authors consider $\mathrm{HC}$ as one of the most effective strategies to promote environmentally friendly transportation activities (Dekker et al., 2012).

One of the first works on $\mathrm{HC}$ in this field is due to Caputo and Mininno (1996), who propose policies related to the use of standardized electronic documents, standardized containers and pallets, coordinated routing plans, merging of different suppliers (consolidation) before the delivery process, etc. Özener et al. (2011) have extensively analyzed both consolidation and coordinated scheduling issues in HC practices. Hageback and Segerstedt (2004) discuss a real-life case involving $\mathrm{HC}$ in rural areas. In some cases, independent carriers might be also interested in cooperating (joining resources) to bid for large-scale truckload shipments. These cooperative efforts show some degree of decentralized or distributed planning, with limited information sharing among partners to guarantee confidentiality of sensitive information (Dai and Chen, 2014). How to allocate both costs and benefits among the transportation partners is one of the main topics in the HC literature (Dai and Chen, 2012). Profit margins of freight carriers due to $\mathrm{HC}$, as well as ways to redistribute these profits, are analyzed in Krajewska et al. (2008). Decision support systems designed to promote HC among enterprises in the transportation sector are introduced in Naesens et al. (2009) and Dahl and Derigs (2011).

Liu et al. (2010) describe some HC experiences in road transportation. In these cases, synergies arise among the cooperating partners, including direct benefits such as: increase in service quality and geographic coverage, reduction of delivery times, etc. As noticed by Lyons et al. (2012), transportation activities constitute complex decision-making problems along the supply chain, i.e., from the supplier of raw materials to the final customers. Decision making in a supply chain not only includes transportation issues, but also other logistics issues that interact with the transportation ones, e.g., the use of a single-echelon or a multi-echelon approach, inventory management, location of warehouses and distribution centers, etc. Therefore, a computational approach based on the use of intelligent algorithms is required to support these decision-making processes. Hence the term "computational logistics". In fact, many relevant works on HC in transportation and logistics are strongly related to the development of optimization algorithms, e.g.: Cruijssen et al. (2010) or Anand and Bahinipati (2012), just to name a few examples. Most of these works include several versions of pick-up and delivery problems, where carriers cooperate with each other in order to improve the global efficiency of the delivery and collecting process. Zhou and Wang (2015) also explore similar problems in a realistic environment where several enterprises deliver their products from the same depot and share their trucks to satisfy their customers' demands. Their study shows the impact of cooperation among these enterprises by considering a global Vehicle Routing Problem (VRP) instead of several individual VRPs. Similar problems and solving approaches are described in PérezBernabeu et al. (2015) and Quintero-Araujo et al. (2017).

\section{HC in Telecommunication Services}

This section examines $\mathrm{HC}$ actions among similar and usually competing, telecommunication companies (telecoms). Cooperation in the telecommunications field can be either enforced by governments or voluntarily adopted by the telecoms. Governments regulate the telecommunications market for the benefit of society, citizens, public organizations and other private sector companies (OECD, 2014). For example, governments regulate the spectrum. In order to transmit information, telecoms may share the spectrum either geographically (different telecoms use the same frequencies at different locations) or temporarily (different telecoms use different frequencies in the same area). In parallel, telecoms form voluntarily alliances to mutually exploit their resources, infrastructure, technology, expertise and markets (Yami and Nemeh, 2014). These companies must provide to their customers the ability to communicate among themselves as well with customers of other telecoms. Therefore, from the very nature of the telecommunications field, the telecoms must interconnect their networks. Thus, a first type of HC already exists. In addition, telecoms should cooperate to manage their networks and provide services to their customers. For example, they must cooperate for synchronization, naming, addressing, information (e.g., data, voice, multimedia) transmission, roaming, etc. In fact, sharing was one of the main reasons for the development of telecommunication networks (Fig. 3). Various users, machines and applications share the network resources, e.g., spectrum, channels, antennas and routers in order to achieve their goals (Fathi, 2015). Also, for decades telecoms were sharing satellites and submarine communication cables. Since the start of the telecommunications deregulation in the 1980s, new entrants appeared which exploited several models of network sharing, such as: roaming, site sharing, ducks and optical fibers. However, the real explosion of network sharing agreements started about twenty years ago. Recently, there is an explosion of network sharing agreements among telecoms, especially in Europe. 


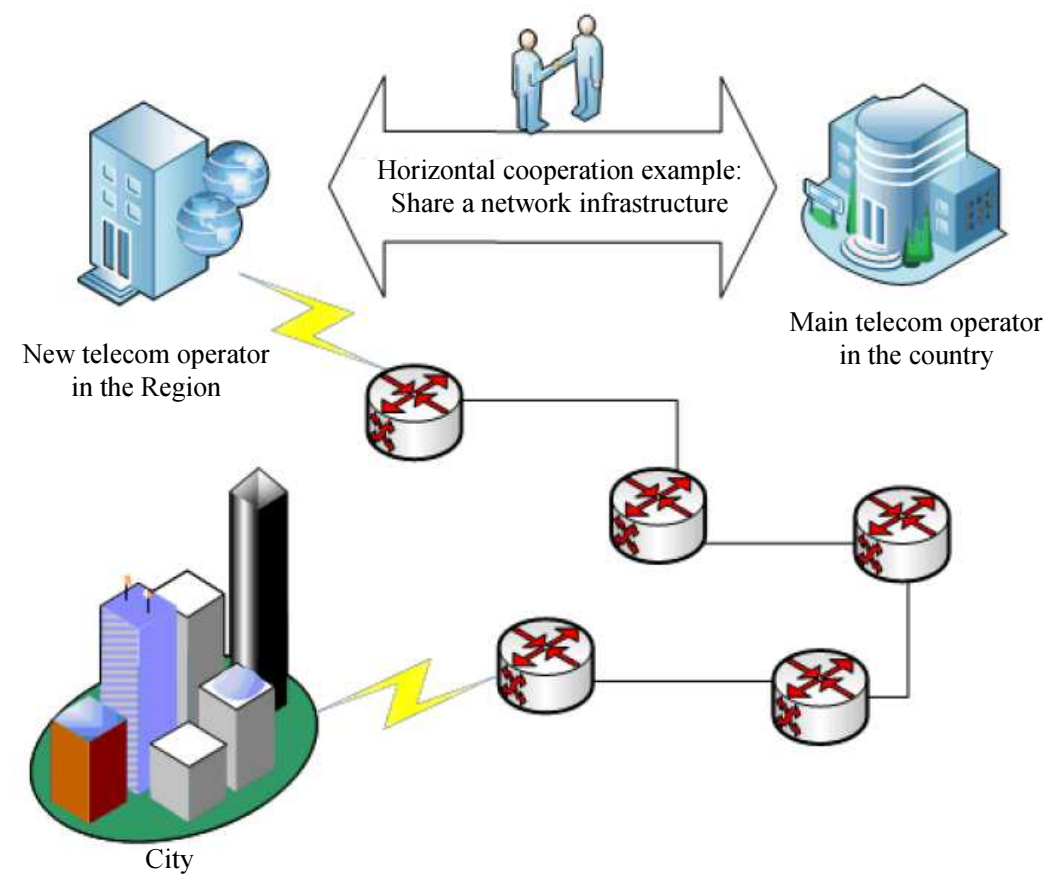

Fig. 3: An example of $\mathrm{HC}$ action in telecommunication networks by sharing an existing network infrastructure

Network sharing is also attractive for covering large geographical areas with low population density like Africa or Brazil. The network resources that companies usually share in their horizontal cooperation systems include passive components (e.g., space, buildings, shelters, poles, towers, electric supply, ducts, or trenches) and active components (e.g., base stations, microwave radio access equipment, antennas, or switches). Currently the most commonly shared infrastructure among telecoms is passive infrastructure, as it is easier to contract its set-up and maintenance. Passive infrastructure sharing started with mobile phone towers.

Usually, telecoms in emerging/developing markets adopt passive sharing to widen coverage and increase capacity. Telecoms in mature markets adopt active sharing to optimize access transmission (Meddour et al., 2011), which is a more complex process. The levels at which telecoms can cooperate depends on the components they share. These levels can be combined in telecoms' agreements. They are listed below in increasing-complexity order:

1. Passive site sharing is the easiest and most commonly implemented form of network sharing. The telecoms share a site (e.g., physical space, ground, rooftop, shed, or cabinet), where each one installs its own equipment separately from that of the other. However, they may also decide to share support equipment such as shelters, power supply, battery back-up, air-conditioning, lighting, security, alarms, fire extinguishers, etc. This can happen on a site-by site basis
2. Passive mast or tower sharing. Each operator installs its own antennas on a shared tower. This can happen on a tower-by-tower basis

3. Radio access network sharing. Cooperation here involves the sharing of all access network equipment (antenna, feeder cable and transmission equipment) to the point of connection with the core network. At this interconnect point each telecom then splits out its traffic on its own core network. High cost saving can be achieved by removing duplicate equipment

4. Multi-operator Radio Access Network (RAN) sharing. The telecoms also share the multi-radio base stations (base transceiver station, etc.) and possibly the radio network controllers and base station controllers. Each telecom maintains its own cell level parameters and only site level parameters are shared

5. Multi-operator core network sharing, where in addition to equipment, the frequencies are shared. Usually it is not allowed be the regulator since spectrum is allocated to individual telecoms. The telecoms share site and cell level parameters. They can have shared RAN and own dedicated RAN

6. Gateway core network sharing, where RAN and core network elements such as the mobile switching center are shared

7. Roaming-based sharing with shared RAN and gateway core, where one telecom relies wholly on another telecom for coverage, but separate core networks are maintained. Thus, traffic from one telecom's subscriber is being carried and routed on another telecom's network 
8. Roaming-based sharing with full network sharing, where each telecom separately works as a Mobile Virtual Network Operator (MVNO). Each MVNO manages its own identification, authentication and billing information systems and shares the rest of the network

The more degree of network sharing, the more complexity and inter dependence of the telecoms. In the more sophisticated sharing forms, it is difficult to exit in case of a dispute between the telecoms. There are some problems that appear due to network sharing such as the disagreements on the objectives or decisions between telecoms, the establishment of network coverage and control indicating when operators should compete and when they can collaboratively share, etc. The main challenges in this area are analyzed in next section. To deal with most of them, telecoms should commit to transparency, clear agreements and willingness to cooperate and share. Otherwise, the network-sharing alliances run the risk of failure. Despite the drawbacks, several forces drive to network sharing. For instance: the emergence of regulatory obligations, the limited spectrum licenses, the need for affordable services, the need for coverage of rural and less populated areas, the limited funds and economic pressure, the high costs of building and operating networks, the difficulty for a new entrant to compete the incumbent, the increased customers' requirements, the new mobile applications with high quality requirements, the traffic congestion at urban areas, the emergence of new technologies, the increased specialization and the need for environmentally friendly developments (e.g., landscape usage and energy consumption).

In order to classify $\mathrm{HC}$ actions regarding network sharing, we can take into account not only the levels of cooperation explained above, but also the following variables:

- Technology: mobile (4G, 5G, etc.), optical fibers (GPON, XG-PON, etc.), satellite, etc.

- Number of participant telecoms: usually two, sometimes three or more (for roaming)

- Age of telecom: a new entrant or an existing telecom

- Size of telecom: small, medium, or large

- Geographical coverage: urban, suburban, rural, or deserted areas

- Country regulatory issues

- Market: developed or developing

- Infrastructure ownership: retention, joint venture, sell and lease back, or exchange

- Development phase: building or operating and maintaining

- Evolution stage towards a new shared network: build a new shared network, combine/integrate their existing networks, or expand/improve their existing networks to a new shared network

- Time length: short-term, medium-term, or long-term

Examining real network sharing cases, some conclusions can be derived. Firstly, network sharing is most beneficial for a new entrant. As stated before, regulatory authorities force telecoms to network sharing to cover rural and less populated areas. Secondly, passive sharing is a simple and popular type of collaboration. It is suitable both for densely populated areas with limited availability (e.g., underground subway tunnels) and for rural areas with high transmission, power and maintenance costs. While active sharing is a more complicated type of collaboration, roaming is simple and popular. Thirdly, telecoms usually prefer to create a new joint venture company that will build, operate and maintain their common infrastructure.

\section{Common Challenges and Opportunities}

Regardless of the sector, HC actions involve many benefits for the cooperating parties. However, previous research made evident several important issues that remain unsolved and need a more persuasive answer. In the field of Internet-based higher education, the opportunities can be summarized as follows. First, thanks to this cooperation there is a social and cultural development, so international or intercultural understanding rises. Second, the mobility and exchange of students and teachers contribute to a better curriculum development and promote teaching and research collaborations, leading to a higher knowledge production. This way, academic standards are needed and, by adopting them, a quality enhancement occurs. Finally, it is important to notice that $\mathrm{HC}$ experiences in this sector leads to an economic growth and to a raise in competitiveness. However, these opportunities in the higher education sector involve five main challenges: (i) coordination continues to be a complex issue in planning and implementation among all the actors taking part in international $\mathrm{HC}$ action and functioning at the same level -national, regional, local, etc.; setting up effective coordination mechanisms at horizontal level, mainly based on strategic institutional cooperation or knowledge creation (e.g., technical tools) is essential to improve performance in higher education policy making; (ii) issues of knowledge management demand ways to "formalize" the new knowledge produced, appropriately apply the new knowledge that is being circulated and adapt and personalize it to the local needs of each country; (iii) one should explore the type of "sound" policies that have to be developed in order to promote more effective teacher education and professional development; it is necessary to consider new international and regional frameworks in order to complement regional practices and policies, especially in the areas of quality credit transfer, assurance, 
accreditation, recognition of qualifications and mobility of students; (iv) $\mathrm{HC}$ in higher education follows a rather complex multilateral or multidirectional pattern, involving multiple parties in both public and private sectors: the national and local governments and universities, citizens of local communities, companies, social and educational organizations, private educational enterprises and non-profit organizations; it becomes necessary for universities and their department of administrative and policy studies to avoid being closed and passive, as well as to make efforts to provide transparency and welcome cooperation from diverse parties; similarly, national and local governments should provide reforming solutions to their bureaucratic "sectionalism" for an organization-wide commitment to education; and (v) being in the Internet and knowledgebased society era, the latter is expected to play a very important role in promoting and strengthening horizontal cooperation in higher education; this passes from an "intelligent" as well as wider participation of society in education and vice-versa; for instance, a new integrated mechanism could be established to combine higher education with social education or bring universities much closer to the local communities through open and online lifelong learning programs.

In the field of the logistics and transportation, as extensively discussed in Cruijssen et al. (2007) some of the main opportunities provided by $\mathrm{HC}$ experiences are: an increase in the company's productivity for core activities, an improvement in the customer service due to the cooperative specialization and the complementary goods and services, a safeguard for companies in uncertain market conditions and an enhancement in their competitive position or market power. On the other hand, the main challenges can be summarized in four areas: (i) identifying the right partners; (ii) determining and dividing the gains; (iii) developing a successful negotiation process; and (iv) establishing an effective coordination schema by employing information and communication technologies. Regarding partners, the aforementioned authors distinguish: "the difference in interests, the difficulty in finding partners with whom to cooperate, the difficulty in finding a trusted party/person to lead the cooperation, the difficulty to distinguish oneself towards customers, the high coordination cost due to differences in operating procedures and the risk of losing clientele to competitors/partners". In relation to the gains, it is clear the difficulty in determining the monetary benefits and establishing a fair allocation of the shared workload and the benefits. In the negotiation issue the disagreements over the domain of decisions or the unequal bargaining positions are very common. Finally, regarding coordination and information and communication technologies, the major challenges are the high indispensable costs, the high additional coordinating and controlling cost and the loss of control.

In the telecommunications industry, the cooperated telecoms achieve the following opportunities and benefits from horizontal cooperation. Firstly, there is a clear reduction of costs: costs of building, operating and maintaining their networks, costs and time of network roll-out and deployment and costs of network equipment purchase (collaborative procurement). Secondly, the network capacity and reliability increase, the network expansion into rural and less populated areas is possible and the adoption of new services appears. Consequently, the growing customer demands can be dealt with and the customer satisfaction increases (e.g., better quality, higher speeds, wider coverage, or higher reliability). Thirdly, regarding resources, the horizontal cooperation between telecoms avoids unnecessary duplications (e.g., digging, trenching, building shelters, towers, acquiring permits, or equipment) and enables more efficient resource utilization. Additionally, it makes possible the adoption of new technologies, as well innovative services and business models. Finally, some general benefits of the horizontal cooperation among telecoms are derived from the primitive collaboration. For example, they can share risks with respect to investment, technology, user demand, government decisions, etc. They can also improve their interoperability, compatibility and unification. On the other hand, the top challenges that telecoms face when approaching a partnership with what might be considered a competitor are summarized below (ERICSSON, 2010): (i) regarding the cultural alignment, stakeholder management and sponsorship, there must be a clear direction on how the different organizations will work with each other and what they aim to achieve; (ii) in relation to the network coverage and control, determining coverage areas plays an important role in order to establish when operators should compete and when they should collaboratively share to be able to compete better with others; (iii) regarding the program complexity and risk, the costs can be increased substantially due to slippages and scope changes in the program; thus, it is necessary to assess the key elements early and to mitigate risks within the program design; (iv) there are shareholder and cost pressures; thus, it becomes difficult to balance the maximization of financial benefits and the minimization of the impact on customers and competitive advantage; (v) it is important to consider the network growth, the economics of a significant traffic increase in the networks (e.g., due to mobile broadband and smartphones) might require from a smart combination of capacity increment and upgrades; (vi) the failure of major sharing arrangements can be just caused by not being able to reach agreement on asset valuation, particularly when a necessary aspect of the program is the pooling of assets within a joint venture; (vii) especially when consolidation of existing coverage takes place, network sharing can be a complex undertaking; (viii) regarding vendor risk sharing, sophisticated risk/reward mechanisms are being more and more used throughout many companies so that the risk is shared between the parties; (ix) it is necessary to consider the regulation and 
spectrum; hence, the depth and extent of what is possible and desirable to share can be determined by local competitiveness; in the past, European government bodies and regulators have rejected network sharing deals due to concern over competitiveness; and (x) market dynamics need to be considered, since the number of potential sharing partners is usually only three to five in each country.

\section{Conclusion}

We have analyzed the role of horizontal cooperation experiences in very different industry sectors which are strongly related to information and communication technologies, such as Internet-based higher education, computational logistics and transportation and telecommunication services. In all these sectors, horizontal cooperation strategies might imply an increase in competitiveness throughout reduction in operation costs, an increase in environmental or social responsiveness and an increase in customer satisfaction throughout a higher quality of service. Other expected outcomes of horizontal cooperation practices are: social and cultural developments, internationalization of small and medium enterprises (including R\&D activities), a raise in infrastructure capacities and their reliability, a faster adoption of new technologies, a better access to external funding and financial markets, a reduced exposure to risk, etc. However, as analyzed in the paper, there are also several challenges that must be properly addressed in order to develop effective horizontal cooperation actions. In particular, one shared aspect among the different sectors that has been highlighted is the difficulty in identifying partners with whom to cooperate trustingly. For this reason, it is important to clarify the conditions for people to succeed when working together and clearly determine the responsibilities of each party, as well as to establish a fair mechanism to redistribute the economic or social benefits gained as a result of the cooperation. Hence, companies must balance between both benefits and drawbacks when they plan to develop horizontal cooperation actions. At the same time, they must always consider possible regulations in the area.

\section{Acknowledgement}

This work has been partially supported by the Erasmus+ Program (2018-1-ES01-KA103-049767).

\section{Author's Contributions}

Angel A. Juan: Coordinated the development of the article.

Angel A. Juan and Jesica de Armas: They oversaw the section on computational logistics and transportation.

Thanasis Daradoumis: Was the main leader in the section on Internet-based higher education.

Anastasios Economides: Took care of the section on telecommunication services.

\section{Ethics}

Due to the theoretical nature of the paper, no ethical issues are expected in the future. In any case, contact the corresponding author for any concern regarding this matter.

\section{References}

ACCESS, 2010. Strategies to strengthen collaboration in Higher Education between Europe and South East Asia.

Allen, W., M. Bonous-Hammath, R. Tersanishi and C. Camp-Yeakey, 2012. As the world turns implications of global shifts in higher education for theory, research and practice. Emerald Group Publishing.

Amutabi, M.N., 2013. Home Truths. China and Africa, 10: 14 .

Anand, G. and B.K. Bahinipati, 2012. Measuring Horizontal Collaboration Intensity in Supply Chain: A Graph-Theoretic Approach. Production Planning Control, 23: 801-816.

Bahinipati, B.K., A. Kanda and S.G. Deshmukh, 2009. Horizontal collaboration in semiconductor manufacturing industry supply chain: An evaluation of collaboration intensity index. Computers Industrial Eng., 57: 880-895.

Bayliss, B.T., M. Ponti, M. Savy, D. Tsamboulas and J. Viegas et al., 2012. Report of the High Level Group on the development of the EU road haulage market.

Caputo, M. and V. Mininno, 1996. Internal, vertical and horizontal logistics integration in Italian grocery distribution. Int. J. Physical Distribution Logistics Management, 26: 64-89.

Cruijssen, F., M. Cools and W. Dullaert, 2007. Horizontal cooperation in logistics: opportunities and impediments. Transp. Res. Part E, 43: 129-142.

Cruijssen, F., P. Borm, H. Fleuren and H. Hamers, 2010. Supplier-initiated outsourcing: A methodology to exploit synergy in transportation. Eur. J. Operational Res., 207: 763-774.

Dahl, S. and U. Derigs, 2011. Cooperative planning in express carrier networks-An empirical study on the effectiveness of a real-time Decision Support System. Decision Support Syst., 51: 620-626.

Dai, B. and H. Chen, 2012. Profit allocation mechanisms for carrier collaboration in pickup and delivery service. Computers Industrial Eng., 62: 633-643.

Dai, B., H. Chen and G. Yang, 2014. Price-setting based combinatorial auction approach for carrier collaboration with pickup and delivery requests. Operational Res., 14: 361-386.

Daniel, C., 2012. The 'horizontal cooperation' and the place of Brazil in Latin American scene: The case of Peruvian university students in Brazil. Proceedings of the 2nd ISA Forum of Sociology, Aug. 1-4, Buenos Aires, Argentina. 
Dekker, R., J. Bloemhof and I. Mallidis, 2012. Operations research for green logistics. An overview of aspects, issues, contributions and challenges. Eur. J. Operational Res., 219: 671-679.

Engel, L., M. Reich and A. Vilela, 2014. The Role of Teachers in Quality Education in Latin America and the Caribbean: Exploring New Forms of Horizontal Cooperation. In: Annual Review of Comparative and International Education (International Perspectives on Education and Society, Volume 25), Wiseman, A.W. and E. Anderson (Eds.), Emerald Group Publishing Limited, pp: 269-293.

ERICSSON, 2010. Successful Network Sharing. A structured approach to network sharing - how to benefit while maintaining competitive advantage. Ericsson White paper.

Fathi, M., 2015. A spectrum allocation scheme between smart grid communication and neighbor communication networks. IEE System. J.

Federal Trade Commission, 2010. Horizontal merger guidelines.

https://www.ftc.gov/sites/default/files/attachments/ merger-review/100819hmg.pdf

Guijarro, A.F., R. Juciute, N. McDonald, N. Mozuraityte and A. Unterstaller et al., 2009. Ex-post evaluation of Erasmus Mundus: A final report to DG Education and Culture.

Guri-Rosenblit, S., 2005. Higher Education in Transition: Horizontal and Vertical Patterns of Diversity, In: New Directions in Higher Education, Nata, R. (Eds.) New York: Nova Science Publishers, pp: 23-46.

Hageback, C. and A. Segerstedt, 2004. The need for codistribution in rural areas-a study of Pajala in Sweden. Int. J. Production Econ., 89: 153-163.

King, K., 2014. China's Higher Education Engagement with Africa: A different Partnership and Cooperation Model? In: Education, Learning, Training: Critical Issues for Development, International Development Policy Series No.5, Geneva: Graduate Institute Publications, Boston: Brill-Nijhoff, pp: 151-173.

Krajewska, M.A., H. Kopfer, G. Laporte, S. Ropke and G. Zaccour, 2008. Horizontal cooperation among freight carriers: Request allocation and profit sharing. J. Operational Res. Society, 59: 1483-1491.

Liu, P., Y. Wu and N. Xu, 2010. Allocating collaborative profit in less-than-truckload carrier Alliance. J. Service Science Management, 3: 143-149.

Lyons, A.C., A.E.C. Mondragon, F. Piller and R. Poler, 2012. Network collaboration: Vertical and horizontal partnerships. In: Customer-Driven Supply Chains, Lyons, A.C., A.E.C. Mondragon, F. Piller and R. Poler, pp: 95-111.

Maassen, P., T. Nokkala and T.M. Uppstrøm, 2005. Rethinking Nordic Co-operation in Higher Education National and Institutional Case Studies. Copenhagen: Nordic Council of Ministers.
Meddour, D.E., T. Rasheed and Y. Goruhant, 2011. On the role of infrastructure sharing for mobile network operators in emerging markets. Computer Netw., 55: 1576-1591.

Morosini, M.C., 2011. Internationalization of the knowledge production on Brazilian Higher Education Institutions: International tradition cooperation and international horizontal cooperation. Educação em Revista, 27: 93-112.

Naesens, K., L. Gelders and L. Pintelon, 2009. A Swift Response Framework for Measuring the Strategic Fit for a Horizontal Collaborative Initiative. Int. J. Production Economics, 121: 550-561.

NORDPLUS, 2014. Nordplus Horizontal.

OECD, 2014. Wireless Market Structures and Network Sharing. OECD Digital Economy Papers, No. 243, OECD Publishing. DOI: 10.1787/5jxt46dz19r2-en

Özener, O.O. and O. Ergun, 2008. Allocating costs in a collaborative transportation procurement network. Trans. Sci., 42: 146-165.

Özener, O.O., Ö. Ergun and M. Savelsbergh, 2011. Lane-exchange mechanisms for truckload carrier collaboration. Trans. Sci., 45: 1-17.

Peetijade, C. and A. Bangviwat, 2012. Empty trucks run reduction in Bangkok area: Towards sustainable transportation. Int. J. Trade Economics Finance, 3: 91-95.

Pérez-Bernabeu, E., A.A. Juan, J. Faulin and B.B. Barrios, 2015. Horizontal cooperation in road transportation: A case illustrating savings in distances and greenhouse gas emissions. Int. Trans. Operational Res., 22: 585-606.

Quintero-Araujo, C.L., A. Gruler, A.A. Juan and J. Faulin, 2017. Using horizontal cooperation concepts in integrated routing and facility-location decisions. Int. Trans. Operational Res.

DOI: 10.1111 /itor. 12479

Rosen, D. and A. Vilela, 2011. Twenty-first Century Teacher Education in the Americas: Horizontal Cooperation and the "Inter-American Teacher Education Network" (ITEN). In: Proceedings of Society for Information Technology and Teacher Education International Conference, Koehler, M. and P. Mishra (Eds.), Chesapeake, VA: Association for the Advancement of Computing in Education (AACE), pp: 2909-2912.

Schmoltzi, C. and C.M. Wallenburg, 2011. Horizontal cooperations between logistics service providers: Motives, structure, performance. Int. J. Physical Distribution Logistics Management, 41: 552-575.

Yami, S. and A. Nemeh, 2014. Organizing coopetition for innovation: The case of wireless telecommunication sector in Europe. Industrial Marketing Management, 43: 250-260.

Zhou, Y. and J. Wang, 2015. A local search-based multiobjective optimization algorithm for multiobjective vehicle routing problem with time windows. IEEE Syst. J., 9: 1100-1113. 